\title{
The Use of Computers and Internet as Supplementary Source of Educational Material: A Case Study of the Senior High Schools in the Tema Metropolis in Ghana
}

\author{
Frank W. K. Amenyedzi \\ Mary N. Lartey \\ Beloved M. Dzomeku \\ University of Education, Ghana
}

\begin{abstract}
This study was conducted to assess the computer and Internet usage as supplementary educational material to enhance quality education; help improve educational management and planning; how students use the computers and internet to facilitate their learning; how teachers in the Tema Senior High Schools use the computers and Internet to teach and guide students. Stratified sampling method was used to select students and teachers. The results showed that a significantly high percentage of respondent teachers $(92 \%)$ were computer literate and $78 \%$ of respondent students also had basic knowledge in computer. However, less than $15 \%$ of these teachers used the internet as an innovative way of improving teaching and learning. Over $30 \%$ of the teachers used the computer mainly for research work. Less than $40 \%$ of student respondents used the computer and the Internet facility for entertainment, whereas less than $25 \%$ used it for research and learning. Less than $40 \%$ of respondent students used the Internet for e-mail and browsing. It was revealed that Internet and computers have helped students to achieve new things such as finishing assignments, solving problems, learning history of other countries, improving typing skills, and chatting with friends. There is no clear interaction between teachers and students through the use of Internet facilities. The Internet was not used for guidance. Despite the limited use of computers by teachers in their teaching, many agree that the computer has changed the way students learn. One fourth of teachers have received some form of training in the use of computers, with quite minimal training in the pedagogical integration of ICT. It appears that integration of ICT in Ghanaian school systems is a major step in promoting innovation.
\end{abstract}

Keywords: Computer; Internet; Teaching; Learning; Guidance

\section{Introduction}

The rapid development in Information Communication and Technologies (ICTs) has made tremendous changes in the twenty-first century, as well as affected the demands of modern societies. Recognizing the impact of new technologies on the workplace and everyday life, today's educational institutions try to restructure their educational programs and classroom facilities in order to minimize the teaching and learning technology gap between developed and the developing countries. This restructuring process is providing learners with knowledge of specific subject areas, to promote meaningful learning and to enhance professional productivity (Tomei, 2005). The use of ICTs in Ghanaian schools and African countries is generally increasing and dramatically growing. However, while there is a great deal of 
knowledge about how ICTs are being diffused and used in high schools in developed countries, there is not much information on how ICTs are being used by teachers and students in Ghanaian schools. There is also an assumption that there are wide gaps in the use of ICTs between rural and urban schools (Aduwa-Ogiegbaen \& lyamu, 2005).

Over the years, Ghana has undertaken educational reforms aimed at raising the standard of education. The Junior High School (JHS) system was introduced to equip their graduates with technical and vocational skills while preparing students for the Senior High Schools. In view of the infrastructural challenges facing Ghana's educational system, ICT use, especially computers and Internet, was introduced to increase access and to improve the relevance of education. Currently the educational reform has introduced general educational program of direct class teaching through the Internet or television to thousands of homes in densely populated communities where fewer schools are available.

Elsewhere the computer technology has made it possible for teachers and students to interact through the Internet. ICT are resources that can be deployed to augment existing teaching and learning materials. Haddad et al (2002) identify at least five levels of ICT use in education: Presentation, demonstration, drill and practice, interaction, and collaboration. Websites today abound where instructors and students can visit in order to obtain needed information and interact. This is used in most distance education programs. United Nations Institutions for Training and Research (UNITAR), for instance, uses the Internet as a medium to offer training programs to thousands of public sector workers around the world. The computers have become motivating tools for teaching and learning in schools.

Computers have been used to create electronic libraries and catalogues to enhance academic research work. According to Heeks (1999), "many libraries now provide online resources to facilitate learning and research electronically". Hakkarainen et al. (2000) reported that ICT is a transformative tool and its full integration into the school systems is necessary to prepare students for the information society they will inherit. The Ministry of Education, Science and Sports implemented education reforms in September 2007 with emphasis on ICT. Currently, ICT has been incorporated into the school curriculum, beginning with the pre-tertiary institutions. ICT is now a subject on the schools' timetable from primary to senior high school (Asamoah, 2008).

The Internet allows cost-effective information delivery services, collaborative and distance education, more than has ever been imagined (Clyde, 1995; Todd, 1997).The Internet has myriad websites to help teachers develop or improve lesson plans, exchange ideas, obtain information, and find free animations and simulations to enliven their lessons. According to Awotua-Efebo (1999), most Internet-based collaborative learning projects include teacher support and training, and conference proceedings are published regularly on the Web. Chat rooms or forums may become a laboratory for new ideas. Online study resources can also provide interactive tools for teachers to access feedback from students. Computer based assignments are an effective way of ascertaining students' understanding of concepts. Students also learn more quickly, demonstrate greater retention, and are better motivated to learn when they work with computers (Koert, 2000).

From the early 1990s, education stakeholders in Ghana have been concerned about how teachers and students use computers in schools and how their use supports learning. Teachers use computers to write lesson plans, prepare materials for teaching, record and calculate student grades, and communicate with other teachers. As such, "computers have become a 
routine tool for helping teachers accomplish their professional work" (Becker, Ravitz, \& Wong, 1999). However, many teachers do not facilitate substantial student use of computers for learning activities (Becker, Ravitz, \& Wong, 1999).

Computer-based tests are easier to administer and are quicker to mark. Research shows that the use of computers for drill and practice, and for instructional delivery, combined with traditional instruction, results in increases in learning in the traditional curriculum and basic skills areas, as well as higher test scores in some subjects compared to traditional instruction alone (Fouts, 2002). ICT-enhanced learning mobilizes tools for examination, conclusion, and analysis of information, providing a platform for student inquiry, analysis, and construction of new information. Learners therefore learn as they do and whenever appropriate, work on reallife problems in-depth, making learning less abstract and more relevant to the learner's life situation. In this way, and in contrast to memorization-based or rote learning, ICT-enhanced learning promotes increased learner engagement (Wastson, 2002).

Educational policymakers in Ghana have hailed the introduction of ICT in Ghanaian high schools as a remarkable step that will contribute to knowledge production, communication and information sharing among students and teachers in the school system. However, the commitment of government to the provision of infrastructure for ICT policy implementation has been minimal. Without any direct government investments in provision of ICT resources in second cycle schools, "NGOs and donor organizations in particular, have extended ICT facilities to some schools, mostly in urban communities" (Dankwa, 1997; Parthemore, 2003). Parthemore (2003) points out that many secondary schools in Ghana can now boast of computer laboratories through which students are gaining basic computer literacy. A number of these schools have Internet capabilities, enabling students to deepen their connection to the outside world. The question to ask is how these facilities could be explored to provide greater educational access to these students.

According to Haddad and Drexler (2002), an effective teaching/learning process must stimulate intellectual curiosity and offer a sense of enjoyment that will move the students from the passive role of recipients of information to the active role of builders of knowledge. Yet, engaging the learner in this process can be the most challenging task for teachers. ICTs are effective instructional aids to engage students in the learning process. As learning shifts from the "teacher-centered model" to a "learner-centered model", the teacher becomes less the sole voice of authority and more the facilitator, mentor and coach-from "sage on stage" to "guide on the side". The teacher's primary task becomes to teach the students how to ask questions and pose problems, formulate hypotheses, locate information and then critically assess the information found in relation to the problems posed. Students also learn more quickly, demonstrate greater retention, and are better motivated to learn when they work with computers.

At the inception of the millennium, Ghana's education authorities embarked on a number of projects to introduce ICT into the Ghanaian education set up; especially at the basic and secondary school levels. For instance, in the middle of the 1990s, educational providers realized that Ghanaian professionals could not compete on the global market for jobs because they were limited in skill, especially in the area of Information Technology. Subsequently, the authorities incorporated the study of ICTs as part of the study of science.

Teachers with pedagogical proficiency who are ready and willing to transmit knowledge and support students to construct knowledge will normally make a difference in any learning 
process. In this age of ICT and its integration in the educational system, the role of the teacher, just like in the traditional classrooms, should not be overlooked or underestimated. If teachers possess little knowledge of ICT as is the case of most Ghanaian teachers then the integration of ICT into pedagogical practices is seriously Compromised (Boakye and Banini, 2008).

It is not just acquiring the knowledge of ICT that is important. Teachers need to understand how to use ICT pedagogically. ICT used appropriately can stimulate the development of higher cognitive skills, deepen learning and contribute to the acquisition of skills needed for learning all life- long and for working in today's job market (Tchombe et al., 2008). However, teachers must have opportunities to develop requisite aptitudes, be able to observe or experience constructive learning, and be motivated. In most countries innovation is thought about, invited into educational practices, and pushed down the throats of teachers without warning or preparation (Maclure, 1997). To make innovations and reforms more meaningful, those who will be most directly affected -in schools, this would be teachers, students, parents and administrators- need to be part of the conception and planning process (Samoff et al., 2003; Weva, 2003).

The integration of ICT in Ghanaian school systems is a major step in promoting innovation. However, the educational system currently is bedevilled with myriads of problems including lack of adequate computers and other ICTs tools especially in rural schools, poor Internet connections, inadequate manpower, and lack of coherent ICT policy framework.

The research questions of this study were:

a) How can computers and Internet be used to improve access and participation in education in Tema Metropolis?

b) How can computers and Internet be used to supplement educational material to enhance quality of education in Tema Metropolis?

c) How can computers and Internet help improve educational management and planning in Tema Metropolis?

d) How do students in the Tema Senior High Schools use the computers and Internet to facilitate their learning?

e) How do teachers in the Tema Senior High Schools use the computers and Internet to teach?

f) How the Internet was used for guidance at the Tema Senior High Schools?

\section{Methods}

The study utilized qualitative and qualitative methodology for data collection. The data collection was grounded on the theory of Diffusion of Innovations (Rogers, 2003). According to Rogers, diffusion research focuses on the conditions which increase or decrease the likelihood that members of a given culture will adopt a new idea, product, or practice. Again according to Rogers, people's attitude toward a new technology is a key element in its diffusion.

The study was conducted in three Senior High Schools in the Tema metropolis. The metropolis has about seven Senior High Schools and one Technical school. Simple random sampling was used for data collection. Data was collected on first and second year students of Senior High Schools. The final year classes were exempted because they were as at the time preparing for their West African Senior Secondary School Certificate Examination (WASSCE). Stratified sampling method was used to collect data. 
Three different sets of questionnaires were used for data collection from students, teachers and heads of schools. A total of 120 students were selected from the three schools. Sixty tutors were also selected from the three schools for the study. Respondents (students and teachers) from each program offered in the selected schools were chosen randomly. The study used structured questionnaires and interviews. The methodology was not totally new and employed previously in some studies. Data were subjected to SPSS version 11 analysis using descriptive statistics.

\section{Results and Discussion}

\section{Teachers' ICT Skills and Training}

Teachers were queried about their skills with regard to ICT and its use in their pedagogical practices. A high percentage of the teachers were computer literates (Table 1). High percentage (about $87 \%$ ) of the teachers never use computer in class (i.e. using a computer during class time or taking students to the computer laboratory) (Table 2). This may be attributed to lack of Liquid Crystal Display (LCD) projectors in schools in Ghana.

According to the theory of Gregoire, Bracewell, and Lafarriere (1996) along with John and Sutherland (2004), the "benefit to students of using new technologies is greatly dependent, at least for the moment, on the technological skill of the teachers and the teacher's attitude to the presence of the technology in teaching," it was therefore evident that respondent students were not really benefiting from new technologies in the school. It could be deduced that if the teachers were not technologically knowledgeable, then the benefits of ICT to students would be minimal.

With regard to Internet usage, over $80 \%$ of respondent teachers use the Internet (Table 1 ) and less than $35 \%$ of respondent students were Internet users. The adoption of this innovation may be ascribed to the innovation theory that innovations which are perceived as (a) relatively advantageous (over ideas or practices they supersede); (b) compatible with existing values, beliefs, and experiences; (c) relatively easy to comprehend and adapt; (d) observable or tangible; and (e) divisible (separable) for trial are adopted more rapidly (Rogers, 2003).

Table 1. Improving Access and Participation

\begin{tabular}{|c|c|c|c|c|c|c|c|c|}
\hline $\begin{array}{l}\text { Number of teachers and } \\
\text { students literate in }\end{array}$ & Frea & ncies & & & & centa & & \\
\hline & Teac & & Stuc & & Teac & & Stude & \\
\hline & Yes & No & Yes & No & Yes & No & Yes & No \\
\hline Basic computer skills & 55 & 5 & 94 & 26 & 91.7 & 8.3 & 78.3 & 21.7 \\
\hline Internet application & 51 & 9 & 36 & 84 & 85.0 & 15.0 & 30.0 & 70.0 \\
\hline
\end{tabular}


All three heads of schools intended to install teaching and learning resources on their schools' computers for use by teachers and students. On whether the school's computer laboratory will be linked to any Internet-based library, all three schools responded in the negative. These findings implied that majority of teachers and students were well-equipped with relevant computer skills to undertake computer- based teaching and learning. Nonetheless, teachers use computers to write lesson plans, prepare materials for teaching, record and calculate student grades, and communicate with other teachers.

This corroborated with the study by (Becker, Ravitz \& Wong, 1999: 32). They reported that in situations like this computers become a routine tool for helping teachers accomplish their professional work. However, many teachers do not facilitate substantial student use of computers for learning activities (Karsenti \& Tchaméni-Ngamo, 2007; Newhouse, 1999). If the aspiration of school heads to install learning resources on all computers in the computer laboratory should materialize, it will help in achieving expanded access to education as well as teaching and learning materials. This would support the principle of Watson (2002).

Table 2. Enhancing Quality

\begin{tabular}{|c|c|c|c|c|c|}
\hline \multirow[t]{2}{*}{ Item } & \multicolumn{2}{|c|}{ Frequencies } & \multicolumn{2}{|c|}{ Percentages (\%) } & \multirow[b]{2}{*}{ Total } \\
\hline & Yes & No & Yes & No & \\
\hline Organizing computer-based lessons & 8 & 52 & 13.3 & 86.7 & 100 \\
\hline Giving Internet-based assignment & 6 & 54 & 10.0 & 90.0 & 100 \\
\hline
\end{tabular}

Only about $13 \%$ of respondent teachers organized computer-based lessons (Table 2). Most of them did not organize computer- based lessons because of the limited number of computers in the computer laboratories in the schools. In addition, there was no Internet service connection in the schools' computer laboratories. It was later discovered that the $13 \%$ who organized computer-based learning and teaching are ICT instructors in the schools. Also, with the giving of Internet-based assignments, only $10 \%$ assigned Internet-based work to students. Furthermore, teachers complained about the lack of Internet connection in the school whereas others lack Internet knowledge.

It can be deduced from the above results that approximately $87 \%$ of teacher respondents do not give computer-based assignments. Fouts (2002) however, reported that the use of computers for drill and practice, and for instructional delivery combined with traditional instruction, results in increased learning in the traditional curriculum and basic skills areas, as well as higher test scores in some subjects compared to traditional instruction alone. Teachers should therefore begin to give computer -based assignments and tests in order to increase student's learning experience.

Pelgrum 2001 identified several factors that hinder the diffusion of ICTs in high schools. The study identified four of the factors as personal ideas about the contribution that technology can make to the processes of teaching and learning and classroom management; teachers' lack of knowledge and skills; insufficient number of computers and ICT infrastructure; and difficulty in integrating ICT instruction in classrooms. In a related study, Ely (1993) distinguishes three major conditions, relevant to ICT integration in classrooms. These are dissatisfaction with the status quo, existence of knowledge and skills, and availability of resources. 
Table 3. Computer Usage by Teachers in the Tema Metropolis

\begin{tabular}{lll}
\hline Usage in school & Frequencies & Percentages (\%) \\
\hline Students assessment & 15 & 25.0 \\
Typing of test items & 7 & 11.7 \\
Teaching and learning & 8 & 13.3 \\
Research work & 20 & 33.3 \\
Entertainment & 10 & 16.7 \\
\hline Total & 60 & 100 \\
\hline
\end{tabular}

About $24 \%$ of respondent teachers use the computer for collection of academic data of the students; about $11 \%$ type test items of their students with the computer, about $13 \%$ use it in teaching as Teaching and Learning Materials (TLMs), practical demonstration or for drill and practice (Table 3 ). Only about $13 \%$ were ICT teachers. Less that $35 \%$ of respondents use ICT for research work whereas about $16 \%$ use the facility for entertainment.

\section{Head of Schools Response to the Use of Computers for Educational Management}

The heads of two of the selected schools contended that computer use in education is only relevant to teaching ICT course. The monitoring of students' performance by the heads of schools was undertaken mainly through written assessment cards and from the schools' database. Certainly, an electronic database of the performance of students will improve the speed of retrieval of records. The schools also have plans to improve teachers' delivery through the use of computers and Internet by making them go through some ICT training but this is only possible after acquiring the relevant software to enhance teaching with computers.

Pannell (1998) reported that if an innovation generates observable results in a short span, it is easier to learn about the worth of innovation and its application by the individual. It is also reported that innovation adoption is linked to the relative importance of external influences such as change agents (Roger 2003). In this case the effectiveness of the change agent in facilitating this process is also dependent upon the methodology that is employed. Those methodologies that heighten the sense of ownership among the target population tend to be the most successful in the long term (Lamble \& Seaman, 1994).

With regard to the use of computers and Internet to improve educational management and planning in the Tema metropolis, the heads of schools communicated with parents on issues concerning their wards but not through the Internet. The heads of institutions use means such as terminal academic reports, Parents Teacher Association meetings, telephone calls and letters. There was no use of Internet-based interaction between the schools and parents. This was because the facility was not available. With the directors or educational policymakers, circulars were issued to head teachers to serve as links between the two parties. Information was also given to them through circuit supervisors and regular invitations for meetings with 
the director and administrative supervisors. According to them, the medium was not reliable because letters or circulars either arrived late or were not received at all.

\section{Students' Knowledge and Usage of Computer in Learning}

The study revealed that a high percentage of respondent students have some basic knowledge in computing (Table 1). The results showed that less than $50 \%$ of student respondents used the computer and the Internet facility for entertainment, whereas less than $25 \%$ used the facility for research and learning (Table 4). As regards e-mail usage and browsing, less than $40 \%$ of student respondents used the facility.

Table 4. Computer Usage by Students to Facilitate Learning

\begin{tabular}{lll}
\hline Usage & Frequencies & Percentages (\%) \\
\hline Entertainment & 50 & 41.7 \\
Learning \& Research & 28 & 23.3 \\
Browsing \& Email & 42 & 35.0 \\
\hline Total & 120 & 100 \\
\hline
\end{tabular}

Those who used the facility attested to the fact that Internet and computers have helped them to achieve new things which they could not have done. Some of these were: Finishing assignments, solving questions, use of certain search engines, history of other countries, increased typing skills, chatting with friends, increased scope of research, etc. The few student respondents felt that the introduction of ICTs in their educational institutions has had beneficial impact both on them and on their teachers. According to the students, ICT was enhancing their learning process.

Information gathered on subject based courses respondents stated that the Internet, radio and television were extra reference materials that help to deepen their understanding of the subjects taught in the classrooms. Almost all respondents felt the use of ICT in learning and research has enhanced the development of higher order skills. By higher order skills the respondents meant their computer skills have been enhanced and have resulted in using those skills in other areas of discipline.

They cited online collaboration projects like the Global Teenager Project and other interactive projects have enhanced their global awareness and knowledge of other cultures as positive benefits. Many also felt that online resources have helped them in their academic achievements. The adoption of the computer innovation could be attributed to the trialability theory (Rogers 2003).

Only less than $5 \%$ of respondent teachers in the Tema metropolis used the facility as TLMs. Less than $6 \%$ of teacher respondents used it for practical demonstration; less that $2 \%$ uses it for drill and practice and only less than $4 \%$ use it in all options given (Table 5). 
Table 5. Computer Usage by Teachers in the Tema Metropolis in Teaching

\begin{tabular}{|c|c|c|c|c|c|}
\hline \multirow[t]{2}{*}{ Item } & \multicolumn{2}{|c|}{ Frequencies } & \multicolumn{2}{|c|}{ Percentage (\%) } & \multirow[b]{2}{*}{ Tota } \\
\hline & Yes & No & Yes & No & \\
\hline TLMs & 2 & 58 & 3.3 & 96.7 & 100 \\
\hline Practical demonstration & 3 & 57 & 5.0 & 95.0 & 100 \\
\hline Drill and Practice & 1 & 59 & 1.7 & 98.3 & 100 \\
\hline All & 2 & 58 & 3.3 & 96.7 & 100 \\
\hline
\end{tabular}

When asked the reason for not using it to teach, respondents indicated that the facilities were limited and not connected to the internet. Some also indicated that they did not know how to use it in relation to their subject. Those respondents who used the facility have been able to achieve new things they could not do earlier. Some of these were: Detailed information on issues, information on other books, further areas in their subjects, communication design and logo, planning of scheme of work, etc.

Despite the fact that some teachers do not use ICT at all, teachers generally agreed that the computer had changed the way students learn, with about $96 \%$ responding that computers changed significantly the way students learn. Some of the comments made were that computer use for pedagogical purposes should be intensified and exploited to the fullest. Similar findings were observed by Boakye and Banini (2008). Regarding training, $24 \%$ of teachers said they had received some form of training on using the computer.

Teachers used computers to write lesson plans, prepare materials for teaching, record and calculate students' grades, and communicate with other teachers. As such, computers have become a routine tool for helping teachers accomplish their professional work (Becker, Ravitz \& Wong, 1999). There were indications that teachers proceeded to adopt ICTs in stages. Myhre (1998) reported that teachers initially focus on their own interaction with the new medium, and as they gradually become comfortable with the technology they start deliberating upon learning benefits that would result from the use of the computer. It is the increased familiarity with computers that can allow teachers to turn their interest to the pedagogical use of technology rather than its operational issues Myhre (1998). Waite (2004) indicated that even though teachers showed great interest and motivation to learn about the potential of ICT, in practice, the use was relatively low and it was focused on a narrow range of applications, with word processing being the predominant use.

It was revealed during the study that NGOs and other organizations that provide ICT training for teachers in Ghana rarely conduct an evaluation of prior knowledge to feed training. A few teachers are experimenting the use of ICT intra- and inter-subject to enhance pedagogy. Such practices are likely to take root across the country, but in an uneven fashion depending on access, individual and group initiative, and support from school administration. The broader institutionalization of ICT use in teaching and learning will take more time, though the study did reveal the beginning of promising practices for durability of ICT in schools, such as parent involvement and the creation of school committees responsible for ICT integration. An obvious start has to be the issue of teacher skills. 


\section{Conclusions}

Although ICT skills of teachers in the Tema metropolis are limited, the number of teachers using them was beginning to gradually rise and so are opportunities to learn them. What was observed was the willpower teachers have to learn ICT and ICT integration, which must be harnessed by government without delay. Technical knowledge about computers was as important as experience using computers professionally, but exemplary teachers will have objectives for student use of computers that promote student engagement and thoughtful effort, outside of class time as well as during class (Becker, Ravitz, \& Wong, 1999).

Teacher training and an environment that promotes reflection on teaching practice are vital to support beneficial pedagogical integration of ICTs. Also, while Rogers' theory (2003) on innovation and adoption has been widely acclaimed, its application raises several critical issues. Application of the theory is largely dependent upon highly skilled, highly motivated, effective change agents. It was identified that leadership plays a key role in ICT integration in education. Many teacher- or student-initiated ICT projects have been undermined by lack of support from above.

What was observed was the willpower teachers have to learn ICT and ICT integration, which needed to be harnessed by government. For ICT integration programs to be effective and sustainable, administrators themselves must be competent in the use of the technology, and they must have a broad understanding of the technical, curricular, administrative, financial, and social dimensions of ICT use in education.

In short, integration of ICT in Ghanaian school systems is a major step in promoting innovation. However, the educational system currently is bedevilled with myriads of problems including lack of adequate computers and other ICT tools especially in rural schools, poor internet connectivity, lack of adequate manpower, lack of coherent ICT policy framework. The introduction of ICTs in education in Ghanaian schools therefore had a demonstrated benefit for the future life of students, through the acquisition of both technology skills and academic competencies.

\section{References}

Aduwa-Ogiegbaen, S. E. \& Iyamu, E. O. S. (2005). Using information and communication technology in secondary schools in Nigeria: Problems and prospects. Journal of Educational Technology \& Society, 8(1), 104-112.

Asamoah, D. A. (2008). Learning through ICTs. Available at: http://www.digitallearning.in/ interveiw/ interview-details.asp?

Awotua-Efebo, E.B. (1999). Effective teaching: Principles and practice. Port Harcourt, Nigeria: Paragraphics.

Becker, H. J., Ravitz, J. L., \& Wong, Y. T. (1999). Teacher and teacher-directed student use of computers. Teaching, learning and computing national survey (Report no. 3). Irvine, California, USA: Center for Research on Information Technology and Organizations at the University of California. Available at: www.crito.uci.edu/tlc/findings/computeruse/ 
Boakye, K. B. \& Banini, D.A. (2008). Teacher ICT readiness in Ghana. In K. Toure, T.M.S. Tchombe, \& T. Karsenti (Eds.). ICT and changing mindsets in education. Bamenda, Cameroon: Langaa; Bamako, Mali: ERNWACA /ROCARE.

Clyde, A. (1995). Computers in school libraries: The Internet and Australian schools. ACCESS, 9(2), 26-28.

Dankwa, W. A. (1997). SchoolNet: A catalyst for transforming education in Ghana. [Online]. Available at: http://www.isoc.org/isoc/whatis/conferences/inet/96/proceedings/c6/c6_1.htm.

Ely, D. P. (1993). Computers in schools and universities in the United States of America. Educational Technology, 33(9), 53-57.

Fouts, J. (February 2002). Research on computers and education: Past, present, and future. Retrieved 30 October 2002 from http://www.gatesfoundation.org/nr/downloads/ed/ evaluation/Computer_Research_Summary.pdf

Gregoire, R., Bracewell, R., \& Lafarriere, T. (1996). The contribution of new technologies to learning and technology in elementary and secondary school. Available at: http://www. tact. fse.unlaval.ca/fr/html/impactnt.html

Haddad,W. D. \& Drexler, A.D. (2002). The dynamics of technologies for education. In W. Haddad \& Drexler, A. D. (Eds.) Technologies for education: Potentials, parameters, and prospects. Washington DC: Academy for Educational Development.

Hakkarainen, K., Ilomaki, L., Lipponen, L., Muukkonen, H., \& Rahikainen, M. (2000). Students' skills and practices of using ICT : Results of a national assessment in Finland, Computers and Education, 34(2), 103-117.

Heeks, R. (1999). Information and communication technologies, poverty and development (Working Paper Series, Paper No. 5). Manchester, England: Institute for Development Policy and Management.

John, P.D. \& Sutherland, R. (2004). Teaching and learning with ICT: New technology, new pedagogy? Education, Communication \& Information, 4(1), 102-107.

Karsenti, T. \& Tchaméni-Ngamo, S. (2007). Qualité de l'éducation en Afrique : le role potentiel des TIC. International Review of Education, 53, 665-686.

Koert, R. V. (2000). Providing content and facilitating social change: Electronic media and rural development (Based on case material from Peru). First Monday. http://firstmonday. org/issues/issue5_2/vankoert/index.html

Lamble, W. \& D. Seaman, (1994). Diffusion and adoption: Basic processes for social change. In D. J. Blackburn (Ed.), Extension handbook: Processes and practices (pp. 46-56). Toronto, Canada: Thompson Educational Publishing.

Maclure, R. (1997). Overlooked and undervalued: A synthesis of ERNWACA reviews on the state of educational research in West and Central Africa. Bamako, Mali: ERNWACA. Available at: www.rocare.org/Overlooked and Undervalued.pdf

Myhre, O. R. (1998). I think this will keep them busy: Computers in a teacher's thought and practice. Journal of Technology and Teacher Education, 6(2/3), 93-103.

Pelgrum, W. J. (2001). Obstacles to the integration of ICT in education: Results from a worldwide educational assessment. Computers \& Education, 37, 163-178. 
Pannell, D. J. (1999). Social and economic challenges to the development of complex farming systems. Agroforestry Systems, 45, 393-409

Parthemore, J. (2003). A secondary school computer lab in rural Brong Ahafo: A case study reflection on the future of secondary school computer literacy and computer based distance education in Ghana. Available at:http://www.wess.edu.gh/lab/reports/papers. pdf.

Rogers, E. M. (2003). Diffusion of innovations (5th ed.) New York: Free Press.

Samoff, J., Sebatane, E. M., Dembélé, M. (2003). Scaling up by focusing down: Creating space to expand education reform. Paper presented at the Biennial Meeting of the Association for the Development of Education in Africa. Arusha, Tanzania. 7-11 October 2001. Retrieved 9 June 2008 from www.rocare.org/SCALE7.pdf

Tchombe, T. M. S., Maiga, M., Toure, K., Mbangwana, M. A., Diarra, M. L., \& Karsenti, T. (2008, May). Getting ready for higher education: Role of ICT in secondary schools. Paper presented at the ADEA Biennale. Maputo, Mozambique.

Todd, R. (1997). Information Technology and learning: A never-ending beginning. ACCESS, 11(1), 11-14.

Tomei, L. A. (2005). Taxonomy for the technology domain. USA: Information Science Publishing.

Waite S. (2004) Tools for the job: A report of two surveys of information and communications technology training and use for literacy in primary schools in the West of England. Journal of Computer Assisted Learning, 20, 11-21.

Watson, G. (2002). Models of information technology teacher professional development that engage teachers' hearts and minds. Journal of Information Technology for Teacher Education, 10(1-2), 179-191.

Weva, K.W. (2003, December). Synthesis of studies on the generalization and sustainability of reforms. ADEA biennial meeting. Grand Baie, Mauritius. Retrieved 9 June 2008 from www. adeanet.org/biennial2003/papers/6A_Synthese\%20Weva_ENG_final.pdf

Correspondence: B. M. Dzomeku, University of Education, Winneba, College of Agriculture Education, Mampong Campus, Mampong-Ashanti, Ghana. 